\title{
Level of Obesity and Socioeconomic Factors of a Group of Adult People of Bangladesh: A Factor Analysis Approach
}

\author{
Bhuyan Keshab Chandra ${ }^{1,}$, Fardus Jannatul ${ }^{2}$ \\ ${ }^{1}$ Department of Statistics, Jahangirnagar University, Savar, Dhaka, Bangladesh \\ ${ }^{2}$ Department of Mathematics, American International University- Bangladesh, Dhaka, Bangladesh \\ Email address: \\ kcbhuyan2002@yahoo.com (B. K. Chandra), jannatrinky.du@gmail.com (F. Jannatul) \\ ${ }^{*}$ Corresponding author
}

\section{To cite this article:}

Bhuyan Keshab Chandra, Fardus Jannatul. Level of Obesity and Socioeconomic Factors of a Group of Adult People of Bangladesh: A Factor Analysis Approach. American Journal of Data Mining and Knowledge Discovery. Vol. 4, No. 1, 2019, pp. 8-14. doi: 10.11648/j.ajdmkd.20190401.12

Received: December 5, 2018; Accepted: March 21, 2019; Published: April 13, 2019

\begin{abstract}
The present study was based on data collected from 900 respondents of both urban and rural areas of Bangladesh. Among them 44.3 percent were overweight and obese. Majority (70.6\%) were diabetic patients. With the increase in age significant increase in prevalence rate of obesity was observed. Higher prevalence rate was also observed among housewives. An upward shift of prevalence rate was observed among the higher educated respondents. Overweight and obesity were more among urban residents compared to rural residents and they were thirty two percent more exposed to overweight and obesity. Higher prevalence of obesity was noted among females. The proportion of overweight and obese was higher among them who did not do any physical labor. According to factor weights it was noted that the important factors for variation in the level of obesity were mainly gender variation followed by occupation, education and type of work.
\end{abstract}

Keywords: Obesity Among Adult People, Socioeconomic Factors, Level of Obesity, Odd Ratio, Factor Analysis

\section{Introduction}

The prevalence of overweight and obesity has increased rapidly over the last decades especially in developed countries [1-3]. In 2016 WHO estimated that globally approximately 1.9 billion adults (age $>20$ years) were overweight and more than 650 million adults were obese [4]. Obesity is generally associated to a significantly higher risk of arterial hypertension, diabetes mellitus (DM), hepatic steatosis, hyperdyslipidemia and renal failure $[5,6]$. The major contribution of obesity is to lead the increase in the prevalence of chronic diseases and cancers [7-10]. The most common medical morbidities associated with obesity include impaired glucose tolerance and metabolic syndrome [11, 12]. Behavioral factors have significant effects on metabolic risk. It had been observed in some research findings that youth who do not meet guidelines for dietary behavior, physical activity and sedentary behavior have greater insulin resistance than those who do meet guideline [12].

For this reasons, World Health Organization considers the epidemic a worldwide problem which requires public health intervention [13] that act on different factors associated with overweight and obesity as well as technological changes that have lowered the cost of living of the people so that people can avail sufficient food with required protein. Efforts are needed to improve the economic, political, social and environmental conditions so that congenial atmosphere prevails in the society for maintaining healthy life of the people.

But people are less aware, specially the rural people, of the problem of obesity and the factors responsible for this. Even government and public health planners remain largely unaware of the current prevalence of obesity which is the cause of many diseases [5]. As a result, the factors responsible for obesity and the related diseases are not well identified. The aim of this paper was to identify the socioeconomic factors responsible for obesity and overweight among some rural and urban people of Bangladesh. The important factors for obesity and overweight were identified by factor analysis, where largest factor weight indicated the most important variables $[14,15]$ responsible for obesity. 


\section{Methodology}

The study was based on data collected from both urban and rural people of Bangladesh. As per objective of the study the main target was to collect data from diabetic patients as obesity and diabetes are associated [3, 16, 17]. The investigated diabetic patients were 544. To study the variability of socioeconomic variables for diabetic and nondiabetic people, some respondents were also investigated as a control group. The number of this latter group of respondents was 346. However, among this latter group of respondents also there were 91 diabetic patients. Thus, finally, the analysis was performed using the data of 635 diabetic patients and 265 non-diabetic people.

The data were collected through a pre-designed and pretested questionnaire during the months of May and June, 2015 by some undergraduate and post graduate students of American International University-Bangladesh, most of whom were doctors and nurses, of the department of Public Health and they were associated with public health services. The data were collected from the diabetic patients of the working places of the investigators according to their convenience.

Data have also been collected from parents/guardians of 200 randomly selected students of different disciplines of the university, on the assumption that the respondents would be of normal group of people. But during investigation some of them were found as diabetic patients. However, from the filled-in questionnaires 356 were found in completed form and the information of these 356 respondents were included in the analysis.

The questionnaire contained questions related to sociodemographic characters of each person. Questionnaire also contained questions related to the stage and type of diabetes, treatment stage of disease, pre-cautions against the disease and the stage of complications due to the disease. The latter information were provided by the diabetic patients. The information regarding blood sugar level and blood pressure level were also noted down according to the latest measurement by doctors/diagnostic centers.

Some of the variables observed were qualitative in character and some were quantitative. All variables were transformed to nominal form by assigning numbers to do the factor analysis. The variables included for factor analysis were residence of the respondents, their age, gender, marital status, religion, level of education, occupation, type of work, monthly income and smoking habit. The analysis was done by using SPSS [version 20.0]. The level of obesity was measured by BMI [weight in $\mathrm{kg} /\left(\right.$ height in $\mathrm{m}^{2}$ ] and it is a most commonly used measure of level of obesity [18]. The respondents were classified as underweight [BMI $<20]$, normal [BMI, $20-25]$, overweight [BMI $<30$ ] and obese [BMI $\left.30^{+}\right]$. Factor analysis was done to identify the factors for obesity. In performing factor analysis the inclusion of variables was decided by calculating square of the multiple correlation coefficient [19]. The inclusion was justified as all the $\mathrm{R}^{2}$ values were found significant. Besides the factor analysis, the association of different socioeconomic variables with level of obesity were investigated. Significant association was decided by chi-square test with $\mathrm{p}$-value $<$ 0.05 and odd ratio was calculated for respondents who were overweight and obese compared to normal group.

\section{Results}

It was observed from the analysis that among 900 respondents 7.6 percent were underweight [Table 1] and 19.1 percent of them were from rural area. Maximum (43.1) of the respondents were overweight and 20.9 percent of them were rural people. Obesity was observed among 15.3 percent people and overweight respondents were 34.0 percent. In each level of obesity the majority were from urban area. Of course major respondents $(81.4 \%)$ were from urban area. The differences in proportions of level of obesity according to residential area were not significant $\left[\mathrm{P}\left(\chi^{2} \geq 5.128\right)=0.528\right]$ which indicated that respondents for different levels of obesity were similar for both urban and rural areas. However, urban people were more exposed to overweight and obesity by thirty two percent compared to rural people [O. R.=1.32].

The levels of obesity were significantly different among males and females [Table $2, \mathrm{P}(\chi 2 \geq 27.546)=0.000]$. There were 58.9 percent males among the respondents and 47.2 percent of them were normal. The corresponding figure among females were 37.3 percent. However, compared to males more females were obese. They were in more risk of overweight and obesity by 51 percent compared to males [O. R. $=1.51]$

Table 1. Distribution of respondents according to level of obesity and residential origin.

\begin{tabular}{llllllll}
\hline \multirow{2}{*}{ Level of obesity } & \multicolumn{9}{l}{ Residential origin } \\
\cline { 2 - 8 } & \multicolumn{2}{l}{ Rural } & \multicolumn{2}{l}{ Urban } & \multicolumn{2}{l}{ Total } \\
\cline { 2 - 8 } & $\mathbf{n}$ & $\mathbf{\%}$ & $\mathbf{n}$ & $\mathbf{\%}$ & $\mathbf{n}$ & $\mathbf{\%}$ \\
\hline Underweight & 13 & 19.1 & 55 & 80.9 & 68 & 7.6 \\
Normal & 81 & 20.9 & 307 & 79.1 & 388 & 43.1 \\
Overweight & 53 & 17.3 & 253 & 82.7 & 306 & 34.0 \\
Obese & 20 & 14.5 & 118 & 85.5 & 138 & 15.3 \\
Total & 167 & 18.6 & 733 & 81.4 & 900 & 100.0 \\
\hline
\end{tabular}

Table 2. Distribution of respondents according to level of obesity and gender.

\begin{tabular}{|c|c|c|c|c|c|c|}
\hline \multirow{3}{*}{ Level of obesity } & \multicolumn{6}{|c|}{ Gender } \\
\hline & \multicolumn{2}{|l|}{ Male } & \multicolumn{2}{|c|}{ Female } & \multicolumn{2}{|c|}{ Total } \\
\hline & $\mathbf{n}$ & $\%$ & $\mathbf{n}$ & $\%$ & $\mathbf{N}$ & $\%$ \\
\hline Underweight & 41 & 7.7 & 27 & 7.3 & 68 & 7.6 \\
\hline Normal & 250 & 47.2 & 138 & 37.3 & 388 & 43.1 \\
\hline Overweight & 185 & 34.9 & 121 & 32.7 & 306 & 34.0 \\
\hline Obese & 54 & 10.2 & 84 & 22.7 & 138 & 15.3 \\
\hline Total & 530 & 58.9 & 370 & 41.1 & 900 & 100.0 \\
\hline
\end{tabular}

Obesity and severe obesity were observed almost similar among Muslims and Non-Muslims [Table 3]. But more Muslim respondents (43.8\%) were normal compared to NonMuslim respondents (38.8\%). Significant differences in proportions of obesity among the two religious groups were noted $[\mathrm{P}(\chi 2 \geq 10.82)=0.012]$. But the O. R. $=1.07$ indicated that both the religious groups were similarly exposed to overweight and obesity. 
Among the investigated respondents 92.6 percent were currently married and 43.1 percent of them were normal [Table 4]. Similar normal group was noted among the other group of respondents. However, there was significant differences in proportions of different levels of obesity among the two marital groups of respondents $\left[\mathrm{P}\left(\chi_{2} \geq 22.933\right)=0.028\right]$. The value of O. R. $=0.63$ indicated that those who were not currently married they had less chance to become overweight and obese compared to married respondents.

Table 3. Distribution of respondents according to level of obesity and religion.

\begin{tabular}{llllllll}
\hline \multirow{2}{*}{ Level of obesity } & \multicolumn{2}{l}{ Religion } \\
\cline { 2 - 8 } & \multicolumn{2}{l}{ Muslim } & \multicolumn{2}{l}{ Non-Muslim } & \multicolumn{2}{l}{ Total } \\
\cline { 2 - 8 } & $\mathbf{n}$ & $\mathbf{\%}$ & $\mathbf{n}$ & $\mathbf{\%}$ & $\mathbf{n}$ & $\mathbf{\%}$ \\
\hline underweight & 56 & 7.1 & 12 & 10.3 & 68 & 7.6 \\
Normal & 343 & 43.8 & 45 & 38.8 & 388 & 43.1 \\
Overweight & 267 & 34.1 & 39 & 33.6 & 306 & 34.0 \\
Obese & 118 & 15.0 & 20 & 17.3 & 138 & 15.3 \\
Total & 784 & 87.1 & 116 & 12.9 & 900 & 100.0 \\
\hline
\end{tabular}

Table 4. Distribution of respondents according to level of obesity and marital status.

\begin{tabular}{|c|c|c|c|c|c|c|}
\hline \multirow{3}{*}{ Level of obesity } & \multicolumn{6}{|c|}{ Marital status } \\
\hline & \multicolumn{2}{|c|}{ Married } & \multicolumn{2}{|c|}{ Others } & \multicolumn{2}{|c|}{ Total } \\
\hline & $\mathbf{n}$ & $\%$ & $\mathbf{n}$ & $\%$ & $\mathbf{N}$ & $\%$ \\
\hline Underweight & 56 & 6.7 & 12 & 17.9 & 68 & 7.6 \\
\hline Normal & 359 & 43.1 & 29 & 43.3 & 388 & 43.1 \\
\hline Overweight & 285 & 34.2 & 21 & 31.3 & 306 & 34.0 \\
\hline Obese & 133 & 16.0 & 5 & 7.5 & 138 & 15.3 \\
\hline Total & 833 & 92.6 & 67 & 7.4 & 900 & 100.0 \\
\hline
\end{tabular}

Majority (52.9\%) of the respondents were of age 50 years and above and 48.5 percent of them were normal [Table 5]. The percentages of normal groups among the respondents of ages $25-40$ and $40-50$ were 35.5 and 36.6 , respectively. Levels of obesity was significantly associated with levels of ages $\left[\mathrm{P}\left(\chi^{2} \geq 18.34\right)=0.008\right]$. But if classification of respondents was done into two groups, one group of ages $<40$ years and another group of ages 40 years and above, both the groups were almost similarly exposed to overweight and obesity [O. R.=0.81].

Table 5. Distribution of respondents according to their age groups and level of obesity.

\begin{tabular}{|c|c|c|c|c|c|}
\hline \multirow{2}{*}{ Level of obesity } & \multicolumn{5}{|c|}{ Age groups (in years) } \\
\hline & $<25$ & $25-40$ & $40-50$ & $\mathbf{5 0 +}$ & Total \\
\hline \multicolumn{6}{|l|}{ Underweight } \\
\hline $\mathrm{n}$ & 2 & 9 & 24 & 33 & 68 \\
\hline$\%$ & 10.5 & 7.3 & 8.5 & 6.9 & 7.6 \\
\hline \multicolumn{6}{|l|}{ Normal } \\
\hline $\mathrm{n}$ & 11 & 44 & 102 & 231 & 388 \\
\hline$\%$ & 57.9 & 35.5 & 36.3 & 48.5 & 43.1 \\
\hline \multicolumn{6}{|l|}{ Overweight } \\
\hline $\mathrm{n}$ & 3 & 45 & 101 & 157 & 306 \\
\hline$\%$ & 15.8 & 36.3 & 35.9 & 33.0 & 34.0 \\
\hline \multicolumn{6}{|l|}{ Obese } \\
\hline $\mathrm{n}$ & 3 & 26 & 54 & 55 & 138 \\
\hline$\%$ & 15.8 & 20.9 & 19.3 & 11.6 & 15.3 \\
\hline \multicolumn{6}{|l|}{ Total } \\
\hline $\mathrm{n}$ & 19 & 124 & 281 & 476 & 900 \\
\hline$\%$ & 2.1 & 13.8 & 31.2 & 52.9 & 100.0 \\
\hline
\end{tabular}

Most $(62.6 \%)$ of the respondents were at least graduate and graduate respondents were 40.2 percent. Among graduates 41.7 percent were normal. The overweight group was [Table 6] higher among respondents of all levels of education. More normal people was observed among illiterate respondents. Still they had more chance to become overweight and obese [O. R.=1.23] The level of obesity and level of education were significantly associated $\left[\mathrm{P}\left(\chi^{2} \geq\right.\right.$ 26.376) $=0.034]$.

Table 6. Distribution of respondents according to level of education and level of obesity.

\begin{tabular}{|c|c|c|c|c|c|c|c|c|c|c|}
\hline \multirow{3}{*}{ Level of education } & \multicolumn{10}{|c|}{ Level of obesity } \\
\hline & \multicolumn{2}{|c|}{ Underweight } & \multicolumn{2}{|c|}{ Normal } & \multicolumn{2}{|c|}{ Overweight } & \multicolumn{2}{|c|}{ Obese } & \multicolumn{2}{|c|}{ Total } \\
\hline & $\mathbf{n}$ & $\%$ & n & $\%$ & n & $\%$ & $\mathbf{n}$ & $\%$ & $\mathbf{n}$ & $\%$ \\
\hline Illiterate & 3 & 8.3 & 17 & 47.2 & 6 & 16.7 & 10 & 27.8 & 36 & 4.0 \\
\hline Primary & 11 & 13.3 & 38 & 45.2 & 25 & 30.1 & 9 & 10.8 & 83 & 9.2 \\
\hline Secondary & 19 & 8.7 & 87 & 40.8 & 78 & 35.8 & 32 & 14.7 & 218 & 24.2 \\
\hline Graduate & 23 & 6.4 & 151 & 41.7 & 121 & 33.4 & 67 & 18.5 & 362 & 40.2 \\
\hline Total & 68 & 7.6 & 388 & 43.1 & 306 & 34.0 & 138 & 5.3 & 900 & 100.0 \\
\hline
\end{tabular}


Table 7. Distribution of respondents according to profession and level of obesity.

\begin{tabular}{|c|c|c|c|c|c|}
\hline \multirow{2}{*}{ Profession } & \multicolumn{5}{|c|}{ Level of obesity } \\
\hline & Underweight & Normal & Overweight & Obese & Total \\
\hline \multicolumn{6}{|l|}{ Agriculture } \\
\hline $\mathrm{n}$ & 6 & 21 & 11 & 1 & 39 \\
\hline$\%$ & 15.4 & 53.8 & 28.2 & 2.6 & 4.3 \\
\hline Business $n$ & 13 & 95 & 74 & 27 & 209 \\
\hline$\%$ & 6.2 & 45.5 & 35.4 & 12.9 & 23.2 \\
\hline Service $\mathrm{n}$ & 6 & 65 & 58 & 25 & 154 \\
\hline$\%$ & 3.9 & 42.2 & 37.7 & 16.2 & 17.1 \\
\hline Private $\mathrm{n}$ & 23 & 91 & 73 & 20 & 207 \\
\hline service \% & 11.1 & 44.9 & 35.3 & 9.7 & 23.0 \\
\hline Retired n & 8 & 51 & 33 & 19 & 111 \\
\hline$\%$ & 7.2 & 45.9 & 29.7 & 17.2 & 12.3 \\
\hline Housewife n & 12 & 65 & 57 & 46 & 180 \\
\hline$\%$ & 6.7 & 36.1 & 31.7 & 25.5 & 20.0 \\
\hline Total n & 68 & 388 & 306 & 138 & 900 \\
\hline$\%$ & 7.6 & 43.1 & 34.0 & 15.3 & 100.0 \\
\hline
\end{tabular}

Higher proportion of respondents $(23.2 \%$, Table 7$)$ were businessmen and 45.5 percent of them were normal. Maximum normal group of respondents (53.8\%) was observed among agriculturists. The overall normal group was maximum. Maximum (25.5\%) respondents of obesity was noted among housewives. The proportions of different levels of obesity according to professional variations were significant $\left[\mathrm{P}\left(\chi_{2} \geq 46.472\right)=0.000\right]$. But, all other professional groups of respondents had the similar risk of obesity compared to servicemen [O. R. = 1.04].

The lower income $(<20,000.00$ Taka) group of people were more $(34.2 \%)$ and $48.4 \%$ of them were normal [Table 8]. More respondents of normal group of people were observed (49.0\%) among them who had income 20,000.00 $<30,000.00$.This group of people were 20.2 percent. The data indicated that $54.4 \%$ respondents had income less than $30,000.00$ taka. More overweight people was observed among them who had income 30,000.00 - <40,000.00 taka followed by the group of people who had income $50,000.00+$. Obese group was also more $(30.3 \% 0)$ among them. Significant association was noted between the level of obesity and the level of income $\left[\mathrm{P}\left(\chi_{2} \geq 64.994\right)=0.00\right]$. The value of $\mathrm{O} . \mathrm{R}=0.40$ for higher income group of people compared to other income level did not indicate that rich people had more chance to become obese and overweight.

Table 8. Distribution of respondents according to monthly income (In thousand taka) and level of obesity.

\begin{tabular}{|c|c|c|c|c|c|}
\hline \multirow{2}{*}{ Income } & \multicolumn{5}{|c|}{ Level of obesity } \\
\hline & Underweight & Normal & Overweight & Obese & Total \\
\hline \multicolumn{6}{|l|}{$<20$} \\
\hline $\mathrm{n}$ & 30 & 149 & 86 & 43 & 308 \\
\hline$\%$ & 9.7 & 48.4 & 27.9 & 14.0 & 34.2 \\
\hline \multicolumn{6}{|l|}{$20-30$} \\
\hline $\mathrm{n}$ & 13 & 89 & 57 & 23 & 182 \\
\hline \multicolumn{6}{|l|}{$30-40$} \\
\hline $\mathrm{n}$ & 10 & 66 & 76 & 24 & 176 \\
\hline$\%$ & 5.7 & 37.5 & 43.2 & 13.6 & 19.6 \\
\hline \multicolumn{6}{|l|}{$40-50$} \\
\hline $\mathrm{n}$ & 9 & 59 & 49 & 18 & 135 \\
\hline$\%$ & 6.7 & 43.7 & 36.3 & 13.3 & 15.0 \\
\hline$\%$ & 6.1 & 25.2 & 38.4 & 30.3 & 11.0 \\
\hline Total $\mathrm{n}$ & 68 & 388 & 306 & 138 & 900 \\
\hline$\%$ & 7.6 & 43.1 & 34.0 & 15.3 & 100.0 \\
\hline
\end{tabular}

It was noted that [Table 9] 50 percent respondents were involved in official work with or without physical labor. These two groups of people were 450 and 164 of them were overweight. Again, those who were not doing any physical labor $(23.1 \%)$ overweight and obesity was more prevalent among them (51.4\%). But level of obesity was not associated with type of work $\left[\mathrm{P}\left(\chi^{2} \geq 11.905\right)=0.453\right]$. However, risk of overweight and obesity did not depend on involvement of physical labor [O. R. $=0.95]$. 
Table 9. Distribution of respondents according to type of work and level of obesity.

\begin{tabular}{|c|c|c|c|c|c|}
\hline \multirow{2}{*}{ Type of work } & \multicolumn{5}{|c|}{ Level of obesity } \\
\hline & Underweight & Normal & Overweight & Obese & Total \\
\hline No work $\mathrm{n}$ & 0 & 7 & 4 & 4 & 15 \\
\hline$\%$ & 0.0 & 1.8 & 1.3 & 2.9 & 1.7 \\
\hline Only official work n & 19 & 102 & 82 & 30 & 233 \\
\hline$\%$ & 27.9 & 26.3 & 26.8 & 21.7 & 25.9 \\
\hline Official work and physical labor $n$ & 15 & 92 & 82 & 28 & 217 \\
\hline$\%$ & 22.1 & 23.7 & 26.8 & 20.3 & 24.1 \\
\hline Physical labor $n$ & 16 & 108 & 65 & 38 & 227 \\
\hline$\%$ & 23.5 & 27.8 & 21.3 & 27.5 & 25.2 \\
\hline Work without physical labor n & 18 & 79 & 73 & 38 & 208 \\
\hline$\%$ & 26.5 & 20.4 & 23.9 & 27.5 & 23.1 \\
\hline Total $\mathrm{n}$ & 68 & 388 & 306 & 138 & 900 \\
\hline$\%$ & 7.6 & 43.1 & 34.0 & 5.3 & 100.0 \\
\hline
\end{tabular}

So far we had discussed the results of association of levels of obesity and some socioeconomic characteristics. Now, let us observe the association of level of obesity and prevalence of diabetes. Table 10 showed that 67.6 percent underweight respondents were affected by diabetes. With the increase in levels of body mass index [BMI] the rates of prevalence of diabetes were also increased. There was no significant association between level obesity and prevalence of diabetes $\left[\mathrm{P}\left(\chi^{2} \geq 0.851\right)=0.837\right]$. But overweight and obese respondents were 62 percent more exposed to diabetes compared to other groups of respondents [O. R.=1.62]

Table 10. Distribution of respondents according to level of obesity and prevalence of diabetes.

\begin{tabular}{lllllll}
\hline \multirow{2}{*}{ Level of obesity } & \multicolumn{9}{l}{ Prevalence of diabetes } \\
\cline { 2 - 7 } & \multicolumn{2}{l}{ Yes } & \multicolumn{3}{l}{ No } & \multicolumn{3}{l}{ Total } \\
\cline { 2 - 7 } & $\mathbf{n}$ & $\mathbf{0}$ & $\mathbf{n}$ & $\mathbf{\%}$ & $\mathbf{n}$ & $\mathbf{\%}$ \\
\hline Underweight & 46 & 67.6 & 22 & 32.4 & 68 & 7.6 \\
Overweight & 271 & 69.8 & 117 & 30.2 & 388 & 43.1 \\
Obese & 217 & 70.9 & 89 & 29.1 & 306 & 34.0 \\
Severe obese & 101 & 73.2 & 37 & 26.8 & 138 & 15.3 \\
Total & 635 & 70.6 & 265 & 29.4 & 900 & 100.0 \\
\hline
\end{tabular}

In one study [20], it was reported that smoking was one of the factor to increase the level of obesity. The present study also indicated similar result [Table 11]. Among the smokers 47.2 percent were normal and 37.2 percent were overweight. The corresponding figures among non-smokers were 41.3 and 32.5 , respectively. The association between smoking habit and level of obesity was significant $\left[\mathrm{P}\left(\chi_{2} \geq 20.189\right)=0.0 .002\right]$.

Table 11. Distribution of respondents according to level of obesity and smoking habit.

\begin{tabular}{lllllll}
\hline \multirow{2}{*}{ Level of obesity } & \multicolumn{9}{l}{ Smoking habit } \\
\cline { 2 - 7 } & \multicolumn{2}{l}{ Yes } & No & \multicolumn{3}{l}{ Total } \\
\cline { 2 - 7 } & $\mathbf{N}$ & $\mathbf{\%}$ & $\mathbf{n}$ & $\mathbf{\%}$ & $\mathbf{n}$ & $\mathbf{\%}$ \\
\hline Underweight & 19 & 6.7 & 49 & 7.9 & 68 & 7.6 \\
Normal & 133 & 47.2 & 255 & 41.3 & 388 & 43.1 \\
Overweight & 105 & 37.2 & 201 & 32.5 & 306 & 34.0 \\
Obese & 25 & 8.9 & 113 & 18.3 & 138 & 15.3 \\
Total & 282 & 31.3 & 618 & 68.7 & 900 & 100.0 \\
\hline
\end{tabular}

Table 11 Among the smokers 47.2 percent were normal and 37.2 percent were overweight. The corresponding figures among non-smokers were 41.3 and 32.5 , respectively. The association between smoking habit and level of obesity was significant $\left[\mathrm{P}\left(\chi_{2} \geq 20.189\right)=0.0 .002\right]$ and smokers were 21 percent more exposed to overweight and obesity compared to non-smokers [O. R. = 1.21].

\subsection{Factor Analysis}

It was observed that levels of obesity varied differently with the variation of different social factors. Thus, we were in search of identification of most important variables to explain the variation in the levels of obesity in the present data [14]. This was done by factor analysis. The analysis helps to identify the important variables to explain the variation in the data set $[15,21]$. The variables which were included in the analysis were sufficient to explain the variation as $\mathrm{KMO}=0.633, \chi^{2}=$ 256.371 , p-value $=0.000$. The inclusion of the variables in the analysis was justified as communality of no variable was less than 0.4 [22]. The significant multiple regression analysis using one of the included variable as dependent variable and others as explanatory variables also justified the inclusion of the variables for factor analysis. The results related to the justification of inclusion of variables were presented in Table 12.

Table 12. Results related to inclusion of variables for factor analysis.

\begin{tabular}{lllll}
\hline Variable & $\mathbf{R}^{2}$ & $\mathbf{F}$ & p-value & Communality \\
\hline Residence & 0.229 & 29.34 & 0.00 & 0.577 \\
Age & 0.097 & 10.60 & 0.00 & 0.710 \\
Gender & 0.438 & 77.17 & 0.00 & 0.742 \\
Marital status & 0.024 & 2.40 & 0.01 & 0.502 \\
Religion & 0.011 & 1.69 & 0.04 & 0.856 \\
Education & 0.377 & 59.78 & 0.00 & 0.700 \\
Occupation & 0.313 & 44.99 & 0.00 & 0.666 \\
Type of work & 0.240 & 31.16 & 0.00 & 0.489 \\
Income & 0.160 & 18.82 & 0.00 & 0.524 \\
Smoking habit & 0.294 & 41.26 & 0.00 & 0.687 \\
\hline
\end{tabular}

From the analytical results it was seen that all the p-values were less than 0.05 which indicated that the inclusion of variables for factor analysis were justified. Moreover, no 
communality for a variable was less than 0.4 [22]. So, the inclusion of variables were satisfactory. From the results of the communality it could be concluded that the variable marital status was more important followed by gender and education. From the results of the communality of the variables it could be concluded that 85.6 percent variation of the variable marital status would be explained by the extracted factors [22]. Similar percentages of variation for the variables gender and religion were 74.2 and 70.0, respectively. These three variables were more important for the variation in the level of obesity.

Table 13. Coefficients of components.

\begin{tabular}{llllll}
\hline Variables & $\mathbf{1}$ & $\mathbf{2}$ & $\mathbf{3}$ & $\mathbf{4}$ & $\mathbf{5}$ \\
\hline Residence & -0.397 & 0.618 & 0.219 & 0.248 & 0.184 \\
Age & 0.252 & -0.125 & -0.169 & -0.307 & 0.755 \\
Gender & 0.799 & 0.132 & 0.240 & 0.159 & -0.133 \\
Marital status & -0.016 & -0.212 & 0.384 & 0.661 & 0.489 \\
Religion & 0.118 & -0.563 & -0.134 & 0.493 & -0.271 \\
Education & -0.694 & 0.435 & 0.066 & 0.100 & 0.024 \\
Occupation & 0.772 & 0.380 & -0.025 & 0.177 & -0.072 \\
Type of work & 0.612 & 0.147 & 0.432 & 0.111 & 0.228 \\
Income & -0.071 & 0.574 & -0.584 & 0.292 & -0.059 \\
Smoking habit & 0.493 & 0.391 & 0.504 & -0.230 & -0.87 \\
\hline
\end{tabular}

The factor analysis extracted 5 components as these components explained 73.309 percent variation in the observations of obesity. The coefficients of the components were presented in Table 13.

From the factor analysis it was noted that the coefficients of the variables gender was highest followed by occupation, education and type of work. These coefficients were observed from the first component. This component explained 25.733 percent variation in the data of obesity. The second component explained 16.161 percent variation of the data. This information were noted from the characteristic roots of the correlation matrix of the variables, where the roots were $2.573,1.616,1.086,1.053$, and 1.003 . The second component showed that the most important variables to explain the variation in the data of obesity were residence followed by religion and income. The third component showed that the variable income was important for explaining the variability in the obesity. This component explained 10.86 percent variation of the obesity.

\section{Discussion}

The analysis presented here was done from the data collected from 635 diabetic patients and 265 control group of respondents. The respondents were investigated mostly by the doctors and nurses from their working places. The selection procedure was a convenient sampling plan.

The investigated respondents were divided into 4 groups according to their level of obesity, where levels of obesity were decided by their levels of BMI. Around 50 percent respondents were overweight and obese. Higher (71.6\%) prevalence rate of diabetes was noted among the overweight and obese group of respondents. Similar finding was also noted in another study [21]. The prevalence of overweight and obesity were significantly associated with age, religion, education, occupation, marital status, income and smoking habit. Similar results were also noted in separate studies [59, 15, 20 - 21]. Around 50.6 percent people of urban area were overweight and obese. This result was also similar as was observed in another study [21]. Factor analysis also indicated that some of the socioeconomic variables were responsible for increased rates of overweight and obesity.

\section{Conclusion}

The analysis was done from the collected information of 900 respondents. They were classified as underweight (BMI $<20$ ), normal (BMI, $20-<25$ ), overweight (BMI, 25 $-<30)$ and obese $(\mathrm{BMI}=30+)$. The percentages of these four groups of respondents were 7.6, 43.1.34.0 and 15.3, respectively. Most the respondents were in normal and overweight groups. The obesity is one of the risk factor of prevalence of non-communicable diseases [NCD] and it enhances the arterial hypertension, diabetes renal failure etc. [3]. In this study also higher prevalence of diabetes was observed among them.

Among the respondents 84.1 percent were of the age 40 years and above and among them 42.8 percent were overweight and obese. Again, prevalence of diabetes was more among these groups. This finding is similar to that observed in both home and abroad [23-25]. The factor analysis showed that sex, occupation, education and type of work were more important to explain the variation in the level of obesity.

The incidence of obesity cannot be avoided, but its prevalence can be reduced by implementing appropriate action plan. The following actions are very important to reduce the prevalence of obesity. These are:

a) Halt the rise in body weight by encouraging people so that they can take healthy home made food and avoid restaurant food / first food.

b) People may be encouraged to do some sort of physical labor after or before official work. This is for the in service, private or government, people. People may be advised to walk daily for at least half-an-hour.

c) Counseling is needed for the obese children and adolescents.

d) To motivate people so that they become careful about the danger of obesity and its adverse effects of health. The public health authority can play a decisive role for the above steps.

\section{References}

[1] Dhurandhar, N. V. (2001): Contribution of pathogene in human obesity. Drug News \& Perspectives, 7(5), 307-313.

[2] Berg, C; Rosengren, A.; Aires, N; et al (2005): Trends in overweight and obesity from 1985 to 2002 in Goteborg, west Sweden. International Journal of Obesity, 29 (8), 916 - 924. 
[3] Skliros, E. A.; Merkoures. P; Sotiropoulos, A, et al (2008):. The relationship between body mass index and hypertension in elderly Greeks; the Nemea Primary Care Study. Journal of the American Geriatrics Society 56(5), 954-955.

[4] WHO fact sheet at http// www.who.int/nwes - room/ factsheets/detail/obesity-and-overweight, dated February 2018.

[5] Bertino, G; Ardiri, A. M.; Ali, F. T. et al (2006): Obesity and related diseases: an epidemiologic study in eastern Sicily, Minerva Gastroenterol Dietol, 52(4), 379-385.

[6] Calamusa, G; Amodio, E; Costantino, C; Pasquale, M. D, et al (2012): Body mass index and factors associated with overweight and obesity: a cross-sectional study of adult subjects living in a small city of Western Sicily (Italy), IJPH, Vol 9, (3), e7539-1 - e7539- 8.

[7] Prasad, S. B; Fahrtash, F; Malaiapan, Y, et al (2009): Obesity and the metabolic syndrome in patients with acute myocardial infraction; International Journal of Cardiology, 144(3), 450451.

[8] Redon, J;Cifkova, R; Laurent, S et al (2008): The metabolic syndrome in in hypertension: European Society of hypertension position statement, Journal of Hypertension 26(10), 1891-1900.

[9] Basen-Engquist, K; Chang, M. (2011): Obesity and cancer risk: recent review and evidence, Curr Oncol Rep., 13(1), 7176.

[10] Pulgaron, E. R. (2013): Child obesity: a review of increased risk for physical and psychological combordities, Clin. Ther, 35(1), 18-32.

[11] Sinha, R, Fisch, G., Teague, B., Tamborlane W. V., Banyas, B, Allen, K., Savoye, M., Rieger, V., Taksali, S., Barbetta, G., Sherwin, R. S., and Caprio, S. (2002): Prevalence of impaired glucose tolerance among children and adolescents with marked obesity, N. Engl. J. Med., 346, 802-810.

[12] Weiss, R., Dzuria, J., Burgert, T. S., et al (2014): Obesity and the metabolic syndrome in children and adolescents, $\mathrm{N}$ Engl. J. Med, 350, 2362-2374.

[13] WHO, The challenge of obesity in the WHO European region and the strategies for response, Edited by Branca, F, Nikogosion, H; Lobstein, T, Copenhagen, WHO, 2007.
[14] Farzana, F. and Bhuyan, K. C. (2017): Identification of factors responsible for obesity in children and adolescents of some affluent families, Biomed J Sci \& Tech, DOI:10.26717/BJSTR.2018.10.002017.

[15] K. C. Bhuyan: Multivariate Analysis and its Applications, New Central Book Agency(p) Ltd., 2004.

[16] Fardus, J and Bhuyan, K. C. (2016): Discriminating diabetic patients of some urban and rural areas of Bangladesh: A discriminant analysis approach, EMBJ, 11(19), 134-140.

[17] Mokdad, A, H,; Ford, E. S.; Bowman, B. A. et al (2001): Prevalence of obesity, diabetes, and obesity related health factors; JAMA, 289, 76-79.

[18] Paymane Adab, Miranda Pullon (2018): Images of measurement of obesity, BMJ, 360. doi: https/doi,org/10.1136/method bmj.k.1274.

[19] Yutaka, T.(1983): Some criteria for variable selection in factor analysis, Behaviormetrika, 13, $31-45$.

[20] Akter S, Rahaman MM, Sarah Krull Abe, Sultana S. Prevalence of diabetes and their risk factors among Bangladeshi adults: a nationwide survey. WHO, 2014, 92, 204-213 A.

[21] Bhuyan, K. C.; Mortuza, A, and Fardus, J (2018): Discriminating patients suffering from non-communicable diseases: A case study among Bangladeshi adults, Biomed J Sci \& Tech, DOI:10.26717/BJSTR.2018.10.001898.

[22] Kritika Jain: Value of communality, Amity Business School, 2018.

[23] Sudeep S. Silent killer, economic opportunity: Rethinking non-communicable disease, Centre on Global Health Security, 2012, World Bank.

[24] Bhuyan, K. C.; Md. Mortuza, A and Fardus, J9 20170: Socioeconomic factors associated with overweight and obesity: A case study among adult people of Bangladesh, AJSE, 16(2), $119-124$.

[25] Hoque, M. E.; Suhail, A. R. Doli; Munim, M; Kurt, Long(2014): and Louis, W. N.; Prevalence of overweight and obesity among children and adolescents of the Indian subcontinent: A meta analysis approach, Nutrition Review, 77(8), 542-550 